\title{
A Review Study on Different Plants in Malvaceae Family and Their Medicinal Uses
}

\author{
Upama Das and Md Shahidul Islam* \\ Department of Pharmacy, University of science and Technology Chittagong (USTC), Bangladesh \\ *Corresponding author: Md Shahidul Islam, Department of Pharmacy, University of science and Technology Chittagong (USTC), \\ Bangladesh.
}

To Cite This Article: Md Shahidul Islam. A Review Study on Different Plants in Malvaceae Family and Their Medicinal Uses. Am J Biomed Sci \& Res. 2019 - 3(2). AJBSR.MS.ID.000641. DOI: 10.34297/AJBSR.2019.03.000641

Received: May 06, 2019 | Published: May 24, 2019

\begin{abstract}
In this investigation, a total of 5 species under 5 genera belonging to the malvaceae family were mentioned. In this study Taxonomy and traditional medicine practices on Malvaceae family of Chittagong, Bangladesh was carried out. The plants which were used by local people, were surveyed and collected. The members of this family have mucilaginous substance. Stellate hairs are usually present on their young parts. Flower Bracteate/ ebracteate, Bracteolateor Ebractiolate, Pedicellate, Dichlamydeou Spentamerous, complete, actinomorphic, regular, bisexual and hypogynous. Out of the total number of species Abutilon indicum (L.) Sweet., Hibiscus esculentus L., Hibiscus mutabilis L., Hibiscus rosa-sinensis L., were common and Gossypium herbaceum L. was rare species in the study area. Detailed survey has made in gathering information regarding use of medicine has been documented. Usually, the survey in each locality started with the interview of elderly and experienced members, locally known as Hakims. Besides, this the common people of the surveyed localities who themselves have used these plant based for health treatments were interviewed to prove veracity of the curative features of plants. Medicinal uses and data about the treatment of various alignments based on the information gathered by using questionnaires are given subsequently. For each species botanical name, local name, habit, habitat, phenology, status of occurrence, and medicinal uses have been mentioned.
\end{abstract}

Keywords: Malvaceae; Medicinal plants; Activity; Uses

\section{Introduction}

Medicinal plants, also called medicinal herbs, have been discovered and used in traditional medicine practices since prehistoric times. Plants synthesise hundreds of chemical compounds for functions including defence against insects, fungi, diseases, and herbivorous mammals. Numerous phytochemicals with potential or established biological activity have been identified. However, since a single plant contains widely diverse phytochemicals, the effects of using a whole plant as medicine are uncertain. Further, the phytochemical content and pharmacological actions, if any, of many plants having medicinal potential remain unassessed by rigorous scientific research to define efficacy and safety [1]. In the United States over the period 1999 to 2012, despite several hundred applications for new drug status, only two botanical drug candidates had sufficient evidence of medicinal value to be approved by the Food and Drug Administration. A medicinal plant is a plant that is used to attempt to maintain health, to be administered for a specific condition, or both, whether in modern medicine or in traditional medicine. The Food and Agriculture Organization estimated in 2002 that over 50,000 medicinal plants are used across the world [2].
The Royal Botanic Gardens, Kew more conservatively estimated in 2016 that 17,810 plant species have a medicinal use, out of some 30,000 plants for which a use of any kind is documented [3]. In other systems of medicine, medicinal plants may constitute the majority of what are often informal attempted treatments, not tested scientifically [4]. The World Health Organization estimates, without reliable data, that some 80 percent of the world's population depends mainly on traditional medicine (including but not limited to plants); perhaps some two billion people are largely reliant on medicinal plants [4]. The use of plant-based materials including herbal or natural health products with supposed health benefits, is increasing in developed countries [5]. This brings attendant risks of toxicity and other effects on human health, despite the safe image of herbal remedies [6]. Herbal medicines have been in use since long before modern medicine existed; there was and often still is little or no knowledge of the pharmacological basis of their actions, if any, or of their safety. The World Health Organization formulated a policy on traditional medicine in 1991, and since then has published guidelines for them, with a series of monographs on widely used herbal medicines [7]. 
Medicinal plants may provide three main kinds of benefit: health benefits to the people who consume them as medicines; financial benefits to people who harvest, process, and distribute them for sale; and society wide benefits, such as job opportunities, taxation income, and a healthier labour force [8]. However, development of plants or extracts having potential medicinal uses is blunted by weak scientific evidence, poor practices in the process of drug development, and insufficient financing [9]. Malvaceae are distributed widely in tropical and temperate regions. 22 genera and about 125 species of Malvaceae have so far been reported from India. Some of the larger genera, along with their common names/ or number of reported species in parenthesis, include Hibiscus (rose mallow, 300), Sida (200), Pavonia (200), Abutilon (Indian mallow, 100), Alcea (60), Malva (Mallow, 40), Lavatera (25), Gossypium (Cotton, 20), and Althaea (12).

A number of species are pests in agriculture, including Abutilon theophrasti and Madiola caroliniana, and others that are garden escapes. Cotton (four species of Gos-sypium), kenaf (Hibiscus cannabinus), cacao, kola nut, and okra (Abelmoschus esculentus) are important agricultural crops. The fruit and leaves of baobabs are edible, as is the fruit of the durian. The family is recognized by Hibiscus ro-sa-sinensis (rose of China) because of its beautiful large flowers and hundreds of its known cultivated varieties. Cotton (Gossypium), the most important plant of this family from the commercial viewpoint, has been cultivated in India since last 5000 years [10].

\section{Objectives of the Review}

Medicinal plants is very much related to our health culture. Most of the people of Bangladesh are directly or indirectly depends medicinal plants for health problem. The review aims to understand the possibility of medicinal plant as a sustainable livelihood option. The specific objectives are to explore the use of locally produced medicinal plants, to explore the market of medicinal plants in Bangladesh, to know about of the habitat, diversity of medicinal plant, to know about the conversation of medicinal plant, to know about the uses of medicinal plant against several diseases.

\section{Materials and Methods}

The present study in based on the intensive field of the area during the period of June 2018 to April 2019. A total of 5 species under 5 genera belonging to the Malvaceae family were collected and identified. The methods and materials were performed through a systematic search related to Euphorbiacea including the ethnomedicinal practices, phytochemistry and pharmacological studies around the world. The data was collected from online journals, research papers and books, all of which were published in different countries. Search engine websites such as Google, Google Scholar, Pub Med, Science Direct, Research gate and other online collections were utilized in this review to obtain information.

\section{Results and Discussion}

The total description and the medicinal uses of the plants of the Malvaceae family are given below:

\section{Hibiscus rosa-sinensis L [11]}

Taxonomic description: An ornamental shrub or small tree. Leaves ovate-lanceolate, more or less acuminate, irregularly and coarsely serrate towards the top. Flowers large, axillary solitary; corolla $7.5 \mathrm{~cm}$ diam., tubular below, red. Local name: Jaba, English Name: Shoe flower, China rose. Habit: Shrub. Habitat: Gardens. Phenology: January to December (Figure 1).

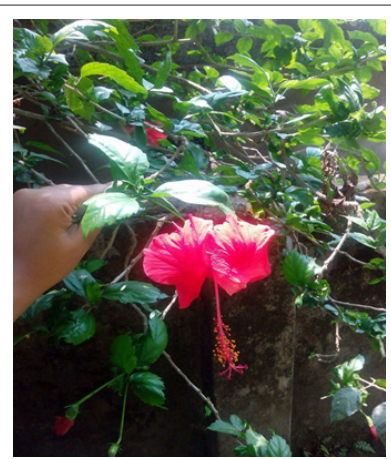

Figure 1: Hibiscus rosa-sinensis L

Medicinal Uses: The flower buds are cooling and as-tringent; remove burning of the body, urinary discharges, seminal weakness and piles. Flowers are refrigerant, emol-lient, demulcent, aphrodisiac and emmenagogue. Juice of the flower with juice of banana inflorescence cures acute dysen-tery. Flower with leaves of Adhatoda zeylanica is very much beneficial in bleeding piles. Flowers fried in ghee is given in menorrhagia; also used in diseases of the genito-urinary tract. Fresh flowers are mecerated and mixed with water is taken to cure scanty menstruation. Staminal column is diuretic and is used in the treatment of kidney trouble. Leaves are emollient, anodyne and aperient. Roots are valuable in cough.

Chemical constituents: Leaves and stems contain $\beta$-sitosterol, stigmasterol, taraxeryl acetate and three cyclopropane compounds and their derivatives. Flowers contain cyanidin diglucoside, flavonoids and vitamins, thiamine, riboflavin, niacin and ascorbic acid. Quercetin-3-diglucoside, 3,7-diglucoside, cyanidin-3,5diglucoside and cyanidin-3-sophoroside-5-glucoside have been isolated from deep yellow flowers; all above compounds and kaempferol-3-xylosylglucoside have been isolated from ivory white flowers.

\section{Abutilon indicum (L) Sweet [12]}

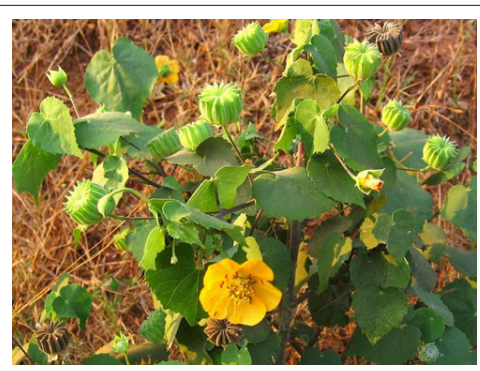

Figure 2: Abutilon indicum (L.) Sweet.

Taxonomic description: An erect woody under shrub. Leaves ovate, cordate irregularly toothed, covered on both surfaces with white down. Flowers solitary, axillary; calyx 5-lobed, tubular below, 
lobes ovate-acute; corolla yellow, petals 5, connate below and adnate to the tube of the stamens. Ripe carpels 15-20, longer than the calyx, truncate or shortly awned. Local name: Petari. Habit: Undershrub. Habitat: In waste places. Phenology: July to August (Figure 2).

Medicinal Uses: Infusion of the leaves and roots is di-uretic and demulcent; used in fevers, chest infections, go-norrhea and urethritis; leaves cooked and eaten in bleeding piles. Stem bark is astringent, diuretic, febrifuge, anthelminticas. lessens perspiration; good in strangury and urinary complaints. Seeds are tonic, aphrodisiac, laxative, emollient and demul-cent; good for bronchitis, cough, piles, gonorrhea, gleet and chronic cystitis. Root is nervine tonic; infusion is useful in fever, leprosy, strangury, piles, leucoderma, haematuria and stones in bladder.

Chemical constituents: chemical constituents of the whole plant of Abutilon indicumhas resulted in the isolation of two new compounds, abutilin A (1) and (R)-N-(1'-methoxycarbonyl-2'phenylethyl)-4-hydroxybenzamide (2), as well as 28 known compounds. The structures of the two new compounds were established on the basis of the spectroscopic analysis, and the known compounds were identified by comparison of their spectroscopic and physical data.

\section{Gossypium herbaceum L [13]}

Taxonomic description:A small, woody, annual shrub. Leaves almost reniform, distinctl cordate-auriculate, 3-5-7 lobed. Inflorescence proliferous, forming many lateral spurs that carry two or more flowers. Bracteoles 3, equalling the capsule, ovate-rotund, top incised into long irregular teeth. Flowers large, yellow with purple claws. Capsules ovoid, acuminate. English name: Cotton. Local name: Karpus Habit: Shrub. Habitat: Cultivated. Phenology: January to December (Figure 3).

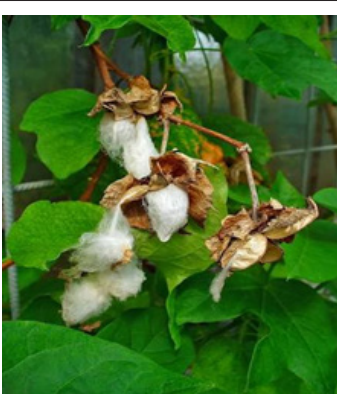

Figure 3: Gossypium herbaceum L.

\section{Medicinal Uses:}

a) Flower extract is used as an abortifacient and to induce menstrual flow.

b) Seeds are demulcent, laxative, expectorant and aphrodisiac.

c) Roots are emmenagogue and galactagogue; useful in dysmenorrhoea and suppression of menstruation.

d) Root bark stimulates uterine contractions and hastens difficult labour. It promotes abortion or onset of menstruation and reduces menstrual flow (Yusuf et al. 2009).
Chemical constituents: Leaves, flowers, roots, stem and seed oil contain an active constituent, a sesquiterpene pigment, called gossypol (a dimeric naphthalene derivative), which causes infertility in men. Other constituents of various parts of the plant include flavonids, quercetin, betaine, choline and salicylic acid. Root bark contains resin.

\section{Hibiscus esculentus L [14]}

\section{Taxonomic Description:}

a) The leaves are alternate, ovate to lanceolate, often with a toothed or lobed margin.

b) The flowers are large, conspicuous, trumpet-shaped, with five or more petals, color from white to pink, red, orange, purple or yellow, and from $4-18 \mathrm{~cm}$ broad.

c) Flower color in certain species, suchas $\mathrm{H}$. mutabilis and $\mathrm{H}$. tiliaceus, changes with age. The fruit is a dry five-lobed capsule, containing several seeds in each lobe, which are released when the capsule dehisces (splits open) at maturity. It is of red and white colours. It is an example of complete flowers. Local name: Dharosh. Habit: Herb. Habitat: Cultivated gardens. Phenology: April to July. Status of occurrence: Abundant (Figure 4).

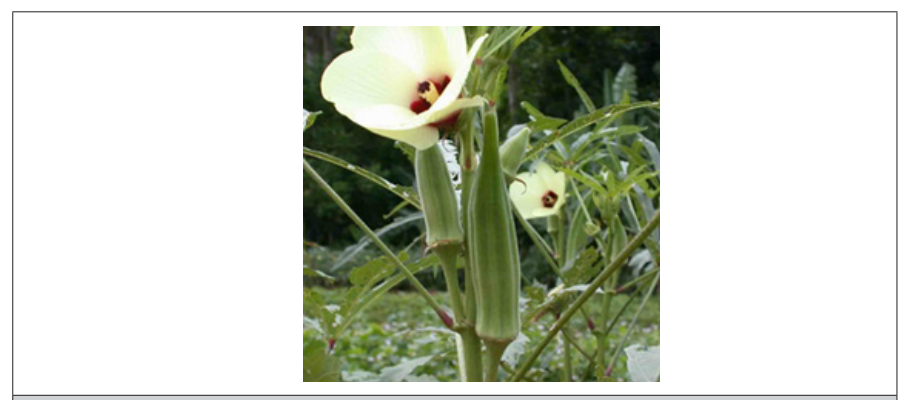

Figure 4: Hibiscus esculentus L.

\section{Medicinal Uses:}

a) The roots are very rich in mucilage, having a strongly demulcent action. They are said by some to be better than marsh mallow (Althaea officinalis).

b) This mu-cilage can be used as a plasma replacement. An infusion of the roots is used in the treatment of syphilis. The juice of the roots is used externally in Nepal to treat cuts, wounds and boils. The leaves furnish an emollient poultice.

c) A decoction of the immature capsules is demulcent, diuretic and emollient. It is used in the treatment of catarrhal infections, ardor urinae, dysuria and gonorrhoea.

d) The seeds are antispasmodic, cordial and stimulant.

e) An infusion of the roasted seeds has sudorific properties.

Chemical Constituent: The leaves are alternate, ovate to lanceolate, often with a toothed or lobed margin. The flowers are large, conspicuous, trumpet-shaped, with five or more petals, color from white to pink, red, orange, peach, yellow or purple, and from 4-18 cm broad. Flower color in certain species, such as H. mutabilis and H. tiliacs, changes with age. The fruit is a dry five-lobed capsule, containing several seeds in each lobe, which are released when the 
capsule dehisces (splits open) at maturity. It is of red and white colours. It is an example of complete flowers.

\section{Hibiscus mutabilis L [15]}

Taxonomic description: A large, bushy, ornamental shrub. Leaves, cordate, long-petioled, suborbicular, 5-7 lobed or angled, softly pubescent or tomentose. Flowers large, axillary, solitary; corolla 7.5-10 cm across, spreading, white or pink. Capsules globose, flattened, hairy. English Name: Changeable Rose, Confederate Rose. Local name: Sthalpadma. Habit: Shrub. Habitat: Gardens. Phenology: July to December. Status of occurrence: Common (Figure 5).

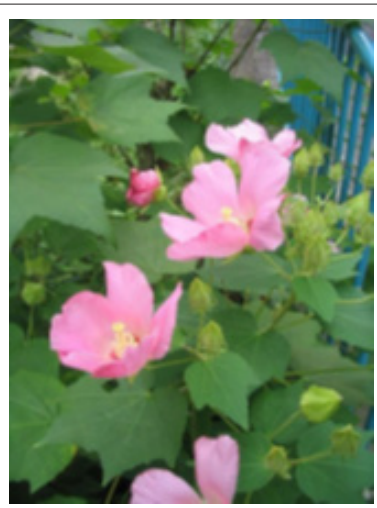

Figure 5: Hibiscus mutabilis L.

\section{Medicinal Uses:}

a) The flowers are considered to be sti-mulant, and an established remedy for pectoral and pulmo-nary complaints.

b) The plant is used as an emollient.

c) The methanol and ethyl extract of this plant habe been reported to posses antibacterial activity against pneumniae, bacillus subtilis, proteus vulgaris, E.coli.

d) The leaves has anti-inflammatory activity.

e) Bark extract of Hibiscus mutabilis has analgesic activity at 50 and $100 \mathrm{mg} \backslash \mathrm{kg}$ respectively.

f) This plant has anti proliferative activity. It also has anti allergic action.

g) Ferulic acid purified from leaf extract of this plant has been used to inhibit lipid induced insulin resistance in skeletal muscel cells.

Chemical Constituents: Flowers contain meratrin, quercimeritrin, cyanin and other flavonoides.

Stem contains flavonoides, glycosides of naringenin and eriodictyol (Asolkar et al., 1992; Rastogi \& Mehrotra, 1990).

\section{Conclusion}

Traditional medicine practices on the family Malvaceae growing throughout Chittagong, Bangladesh was carried out during June
2018 to April 2019. A total of 5 species under 5 genera belonging to the family Malvaceae were collected and identified. The present study may be a preliminary contribution of this area using standard research methods, focusing on medicinal plants and their local uses for the healthcare. This detailed information will be helpful for the pharmacognosist, botanist, ethno-botanist and pharmacologist for the collection and identification of the plant for their re-search work. The result obtained in the investigation need to be rigorously subjected to pharmachemical analysis in order to validate their authenticity and future prospects. The paper has only documented the herbal health remedies presently in vogue in the region and does not prescribe or recommend for their use till further determination by the pharmacologist. Data have been gathered on the traditional uses of plant species, especially for asthma, abscess, anthelmintic, astringent, bronchitis, bedsores, cancer, cough, diuretic, diarrhea, dysentery, eczema, earache, headache, inflammations, jaundice, kidney disease, leprosy, paralysis, skin diseases, scabies, toothache, ulcers, ringworm and others.

\section{References}

1. World Health Organization (2017) "WHO Guidelines on Good Agricultural and Collection Practices (GACP) for Medicinal Plants".

2. Carrubba A, Scalenghe R (2012) "Scent of Mare Nostrum -Medicinal and Aromatic Plants (MAPs) in Mediterranean soils". Journal of the Science of Food and Agriculture 92 (6): 1150-1170.

3. Dharmananda, Subhuti (1997) "The Methods of Preparation of Herb Formulas: Decoctions, Dried Decoctions, Powders, Pills, Tablets, and Tinctures". Institute of Traditional Medicine, Portland, Oregon.

4. Mount, Toni (2015) "9 weird medieval medicines". British Broadcasting Corporation.

5. Pezzuto, John M (1997) "Plant-derived anticancer agents". Biochemical Pharmacology 53(2): 121-133.

6. (2017) "Traditional Medicine. Fact Sheet No. 134". World Health Organization. Archived from the original on 28 July 2008.

7. Chan, Margaret (2015) "WHO Director-General addresses traditional medicine forum". WHO.

8. (2017) “Traditional Chinese Medicine: In Depth (D428)". NIH.

9. Giovannini, Peter (2017) "Managing diabetes with medicinal plants". Kew Gardens.

10. Giovannini, Peter, Howes, Melanie-Jayne R, Edwards, et al. (2016) "Medicinal plants used in the traditional management of diabetes and its sequelae in Central America: A review". J Ethnopharmacol 184: 58-71.

11. Milliken, William (2015) "Medicinal knowledge in the Amazon". Kew Gardens.

12. Yanomami MI, Yanomami E, Albert B, Milliken W, Coelho V (2014) Hwëri mamotima thëpë ã oni. Manual dos remedios tradicionais Yanomami [Manual of Traditional Yanomami Medicines]. São Paulo: Hutukara/ Instituto Socioambiental.

13. (2017) "Medicinal and aromatic plants trade programme". Traffic.org.

14. Collins, Minta (2000) Medieval Herbals: The Illustrative Traditions. University of Toronto Press p. 32.

15. Tapsell LC, Hemphill I, Cobiac L (2006) "Health benefits of herbs and spices: the past, the present, the future". Med J Aust 185 (4 Suppl): S4-24. 